\title{
AOR
}

Selected Papers of \#AoIR2020:

The 21 $1^{\text {st }}$ Annual Conference of the Association of Internet Researchers Virtual Event / 27-31 October 2020

\section{DETECTING COORDINATED LINK SHARING BEHAVIOR ON FACEBOOK DURING THE ITALIAN CORONAVIRUS OUTBREAK}

\author{
Fabio Giglietto \\ University of Urbino Carlo Bo \\ Nicola Righetti \\ University of Urbino Carlo Bo \\ Giada Marino \\ University of Sassari
}

\section{The basic law of rumor}

In their classic essay "An Analysis of Rumor", Gordon Allport and Leo Postman postulated their basic law of rumor (1946). Much in the fashion of other contemporary works of the time, the law is expressed as a mathematical formula stating that "the amount of rumor in circulation will vary with the importance of the subject to the individuals concerned times the ambiguity of the evidence pertaining to the topic at issue" (1946, p. 502).

Following days of constant coverage of the coronavirus outbreak in China, on Friday 21, 2020 Italian citizens woke up with the news of the first native infected patient, lacking any apparent link with China, who was hospitalized in serious conditions.

One of the most high-impact types of data void is that fueling a sudden response to a breaking news case (Golebiewski \& boyd, 2018). Thus, the importance of a topic rich in ambiguity (e.g. the origin of contagious, dubious transparency of data reported by China's authorities, etc.) and lacking evidence (e.g. brand new unknown virus, no vaccine or effective drugs) suddenly spiked the general attention on news about that specific topic (Fig. 1). 


\section{AOR}

Selected Papers of \#AoIR2020:

The 21 $1^{\text {st }}$ Annual Conference of the Association of Internet Researchers Virtual Event / 27-31 October 2020

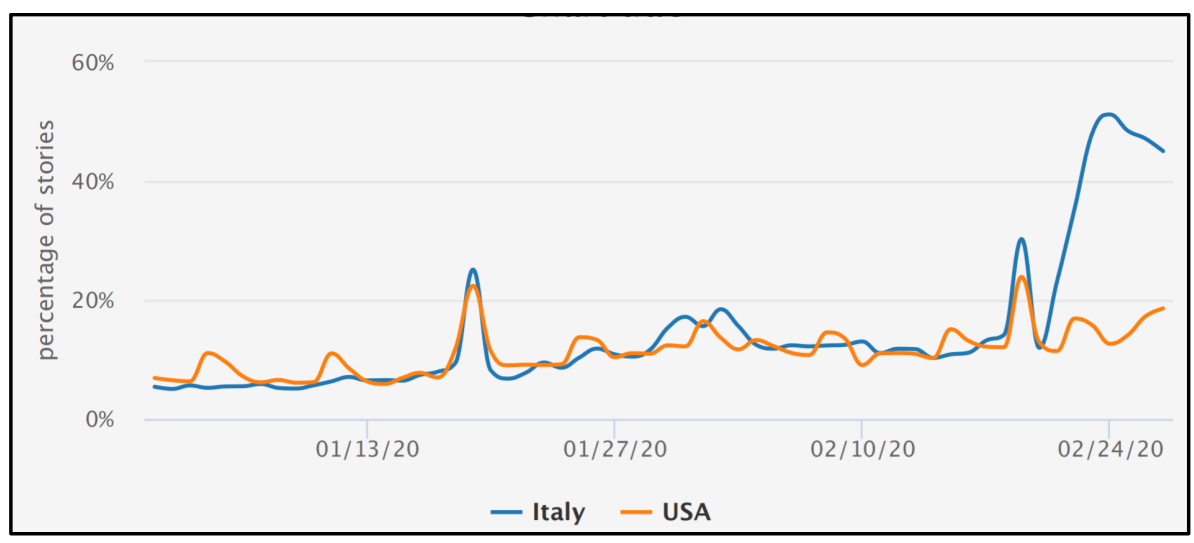

Fig. 1 - Normalized news story percentage of coronavirus OR covid-19 OR "2019nCoV" news stories in Italy and the United States (courtesy of MediaCloud)

Given what postulated by the aforementioned law, a spike of interest on an ambiguous topic multiplies the amount of rumors in circulation. As a corollary, we also expect a corresponding spike in the amount of activity performed by social media actors willing to manipulate the media (Marwick \& Lewis, 2017).

Against this backdrop, we designed a study aimed at observing, under this peculiar condition, the behavior of a set of Facebook pages, groups, and verified public profiles networks identified during previous studies (Authors, 2019) for the way they coordinated their posting strategy to spread problematic information (Jack, 2017).

\section{Coordinated link sharing behavior}

Coordination can be defined as the act of making people and/or things involved in organized cooperation. According to several scholars, it is a distinctive mark of users' participation in digital spaces (Bruns et al., 2013; Jenkins, 2006; Shirky, 2008), and plays a key role in online participatory culture (Jenkins, 2008). Activists benefited from the opportunity provided by the Internet for building online communities and coordinating their actions (Bennett \& Segerberg, 2012) for good purposes, but the same strategies and infrastructures can also be employed by malicious actors (Jenkins, Ito, boyd, 2015; Marwick \& Lewis, 2017).

Social media, as many scholars have shown, can be used to influence political behavior through coordinated disinformation campaigns in which participants pretend to be ordinary citizens (online astroturfing) (Zhang, Carpenter, \& Ko, 2013). With a specific reference to Facebook, a recent study (Authors 2019) has spotlighted patterns of coordinated activity aimed at fueling online circulation of specific news stories before Suggested Citation (APA): Giglietto, F., Righetti , N., Marino, G. (2020, October). Detecting Coordinated Link Sharing Behavior on Facebook During the Italian Coronavirus Outbreak. Paper presented at AolR 2020: The 21 $1^{\text {th }}$ Annual Conference of the Association of Internet Researchers. Virtual Event: AolR. Retrieved from http://spir.aoir.org. 


\section{AOR}

Selected Papers of \#AoIR2020: The 21 $1^{\text {st }}$ Annual Conference of the Association of Internet Researchers Virtual Event / 27-31 October 2020

the 2018 and 2019 Italian elections, an activity called by the authors "Coordinated Link Sharing Behavior" (CLSB). More precisely, CLSB refers to the coordinated shares of the same news articles in a very short time by networks of entities composed by Facebook pages, groups, and verified public profiles. This strategy represents a clear attempt to boost the reach of content and game the algorithm that presides over the distribution of the most popular posts (Author 2019).

Noticeably, CBLS has been proven to be consistently associated with the spread of problematic information: overall, URLs belonging to problematic domains blacklisted by Italian fact-checkers organizations were, before the 2018 and 2019 Italian elections respectively, $1.79(95 \% \mathrm{Cl}[1.08,2.96])$ and $2.22(95 \% \mathrm{Cl}[1.35,3.67])$ times more likely to be shared in coordinated than in non-coordinated way (Fig. 2). Moreover, the coordinated entities are far more likely to be included in the blacklist of Facebook entities compiled by Avaaz (Fig. 3) (Authors, forthcoming).

\section{Problematic domains and coordinated activity}

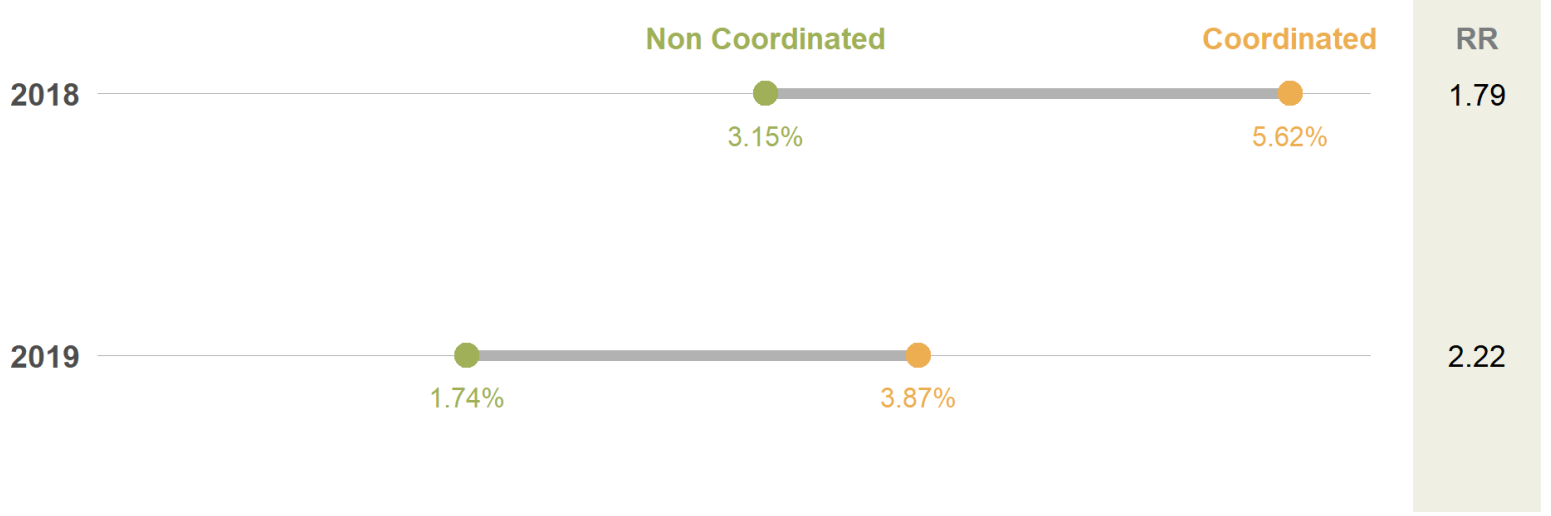

Fig. 2. Proportion of problematic domains shared by coordinated and noncoordinated entities. On the right the risk ratio $(R R)$ values, all statistically significant. 


\section{AOR}

Selected Papers of \#AoIR2020:

The 21 ${ }^{\text {st }}$ Annual Conference of the Association of Internet Researchers Virtual Event / 27-31 October 2020

\section{Problematic Facebook entities and coordinated activity}

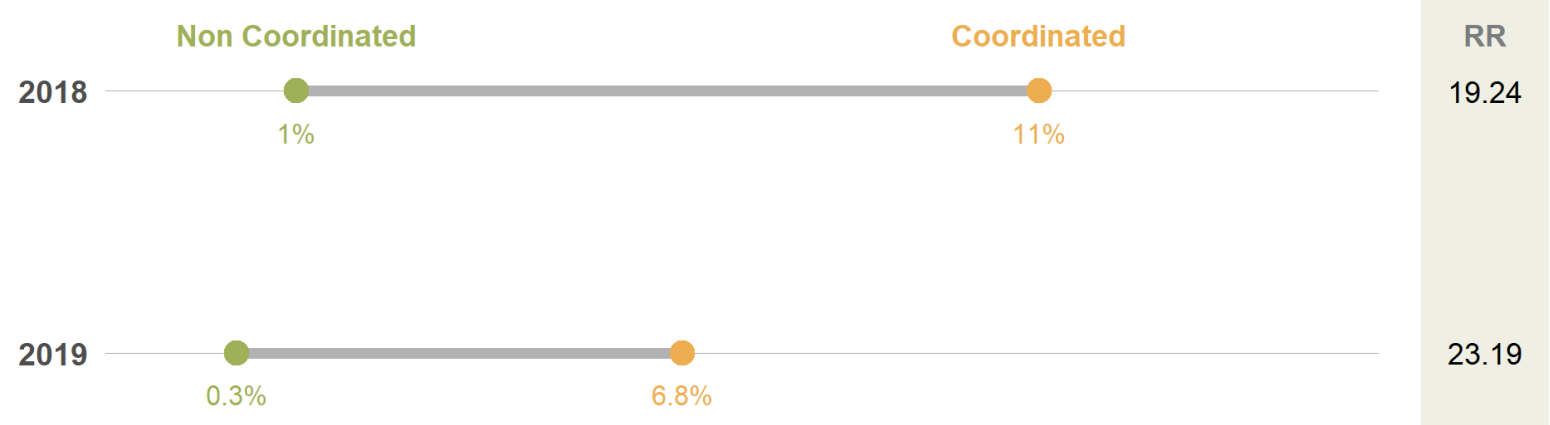

Fig. 3. Proportion of problematic entities included in the coordinated and noncoordinated entities. On the right the risk ratio $(R R)$ values, all statistically significant.

\section{Coordinated networks during the coronavirus Italian outbreak}

The uncertainty related to the coronavirus outbreak is a unique chance for malicious actors to leverage the anxiety of online publics to reach their goals, filling the information void with problematic content. Considering the association between coordination, media manipulation, and problematic information, the entities involved in coordinated online activities represent a privileged perspective on these phenomena.

Moreover, while a certain amount of attention is paid to coordinated behaviors during a longer timespan, usually in the run-up to relevant political events, less is known about these efforts in relation to single breaking-news incidents. The spike of attention on Covid-19 produced, therefore, a unique opportunity to analyze CLSB.

Relying on the list of coordinated entities identified in the above-mentioned studies, we used the CrowdTangle API to collect all the posts including URLs they published between 21 and 24 February 2020. The query resulted in a dataset of 12,502 unique URLs shared 22,900 times. By using the method we developed to identify CLSB, we detected 26 networks composed of 124 entities.

Based on this data, against the backdrop of the literature and the already conducted studies, this proposal will discuss Coordinated Link Sharing Behavior in the context of

Suggested Citation (APA): Giglietto, F., Righetti , N., Marino, G. (2020, October). Detecting Coordinated Link Sharing Behavior on Facebook During the Italian Coronavirus Outbreak. Paper presented at AolR 2020: The 21 $1^{\text {th }}$ Annual Conference of the Association of Internet Researchers. Virtual Event: AolR. Retrieved from http://spir.aoir.org. 


\section{AOR}

Selected Papers of \#AoIR2020:

The $21^{\text {st }}$ Annual Conference of the Association of Internet Researchers Virtual Event / 27-31 October 2020

the coronavirus outbreak informational void, analyzing network mutations over time and the content strategies used to exploit the ambiguity associated with the topic.

\section{References}

Allport, G. W., \& Postman, L. (1946). An analysis of rumor. Public Opinion Quarterly, 10(4), 501-517.

Bennett, W. L., \& Segerberg, A. (2012). The logic of connective action. Information, Communication and Society, 15(5), 739-768.

Bruns, A., Highfield, T., \& Burgess, J. (2013). The Arab Spring and Social Media Audiences: English and Arabic Twitter Users and Their Networks. The American Behavioral Scientist, 57(7), 871-898.

Golebiewski, M., \& Boyd, D. (2018). Data voids: Where missing data can easily be exploited. Data \& Society, 29.

Authors (2019, September 20). Understanding Coordinated and Inauthentic Link Sharing Behavior on Facebook in the Run-up to 2018 General Election and 2019 European Election in Italy. https://doi.org/10.31235/osf.io/3jteh

Authors (forthcoming). It Takes a Village to Manipulate the Media: Coordinated Link Sharing Behavior During 2018 and 2019 Italian elections. Information, Communication \& Society.

Jack, C. (2017). Lexicon of Lies: Terms for Problematic Information. Data \& Society. https://datasociety.net/output/lexicon-of-lies/

Jenkins, H. (2008). Convergence Culture: Where Old and New Media Collide (Revised ed). New York University Press.

Jenkins, H., Ito, M., \& Boyd, D. (2015). Participatory Culture in a Networked Era: A Conversation on Youth, Learning, Commerce, and Politics. John Wiley \& Sons.

Marwick, A., \& Lewis, R. (2017). Media Manipulation and Disinformation Online. Data \& Society.

https://datasociety.net/pubs/oh/DataAndSociety_MediaManipulationAndDisinfor mationOnline.pdf

Shirky, C. (2008). Here Comes Everybody: The Power of Organizing Without Organizations. Penguin Press.

Zhang, J., Carpenter, D., \& Ko, M. (2013). Online Astroturfing: A Theoretical Perspective.

https://aisel.aisnet.org/amcis2013/HumanComputerlnteraction/GeneralPresentat ions $/ 5 /$

Suggested Citation (APA): Giglietto, F., Righetti , N., Marino, G. (2020, October). Detecting Coordinated Link Sharing Behavior on Facebook During the Italian Coronavirus Outbreak. Paper presented at AoIR 2020: The 21 ${ }^{\text {th }}$ Annual Conference of the Association of Internet Researchers. Virtual Event: AolR. Retrieved from http://spir.aoir.org. 


\section{AOR}

Selected Papers of \#AoIR2020:

The $21^{\text {st }}$ Annual Conference of the Association of Internet Researchers

Virtual Event / 27-31 October 2020

Suggested Citation (APA): Giglietto, F., Righetti , N., Marino, G. (2020, October). Detecting Coordinated Link Sharing Behavior on Facebook During the Italian Coronavirus Outbreak. Paper presented at AoIR 2020: The $21^{\text {th }}$ Annual Conference of the Association of Internet Researchers. Virtual Event: AolR. Retrieved from http://spir.aoir.org. 